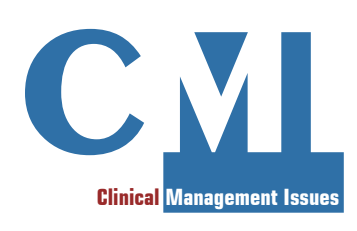

\title{
Stress: How to Help Patients?
}

Stress: come aiutare i pazienti?

CMI 2018; 12(1): 43-48

https://doi.org/10.7175/cmi.v12i1.1359

\section{INTRODUCTION}

Every physician has to face patients whose main pathologies are burdened by high and chronic degrees of stress. Sometimes, stressrelated symptoms are their main pathology. According to Herbert Benson, who pioneered mind-body research and is founder of the Benson-Henry Institute for Mind Body Medicine at Massachusetts General Hospital in Boston, stress is the main cause of medical visits in the USA [1].

Therefore, it is of the utmost importance for the healthcare personnel to know origin and consequences of stress and be able to suggest and teach patients some possible techniques for its management.

\section{MECHANISMS AND CLINICAL CONSEQUENCES}

Stress comes from a well-understood mechanism which aims at preparing the body to a change, that is something that discards the homeostasis (like the attack of a beast or a work stressor). Walter Cannon called this mechanism "fight or flight response" and identified the activation of sympathetic nervous system and the release of epinephrine as its main triggers [2]. After the change occurs (the beast was beaten or the work issue was resolved), the homeostasis is restored. In this view, stress is useful, and even necessary, to face changes in life. In the best cases, homeostasis is restored at a higher level, allowing the individual to obtain an evolutionary advantage [3].

However, if the stress persists too long, several systems are damaged: hippocampal, endocrine, and central nervous system circuits are deregulated, resulting in worsened cognitive and general health conditions [4]. In addition, the secretion of corticotropinreleasing hormone $(\mathrm{CRH})$, norepinephrine, and cortisol

- activates the fear system, thus resulting in anxiety, anorexia, or hyperphagia;

- reduces the satisfaction coming from the reward system, causing depression and eager search for ever greater rewards, often consisting in food; and

- suppresses the sleep system, determining insomnia, night awakenings, and daytime sleepiness.

In addition, the immune system produces cytokines, responsible for the onset of fatigue, nausea, headache, and other pains [3]. Together, all these negative signs are called "sickness syndrome".

Both sides of the stress coin are well caught by Yerkes-Dodson law, represented in Figure $1[5,6]$.

Eustress is helpful to improve the performance, but too high or too prolonged levels of stress are called "distress" and are responsible for the sickness syndrome.
1 Physician, Specialist in Hygiene and Preventive Medicine. Master in Psychoneuroimmunology. AAS N.2. "Bassa Friulana Isontina", Gorizia, Italy 2 Sociologist, First

Researcher, Neuroscience Department, Istituto Superiore di Sanità, Roma, Italy
Corresponding author Cristina Aguzzoli cristina.aguzzoli@gmail.com 
Figure 1. Yerkes-Dodson law. The optimal performance may be obtained when the stress level is moderate. Modified by [6]

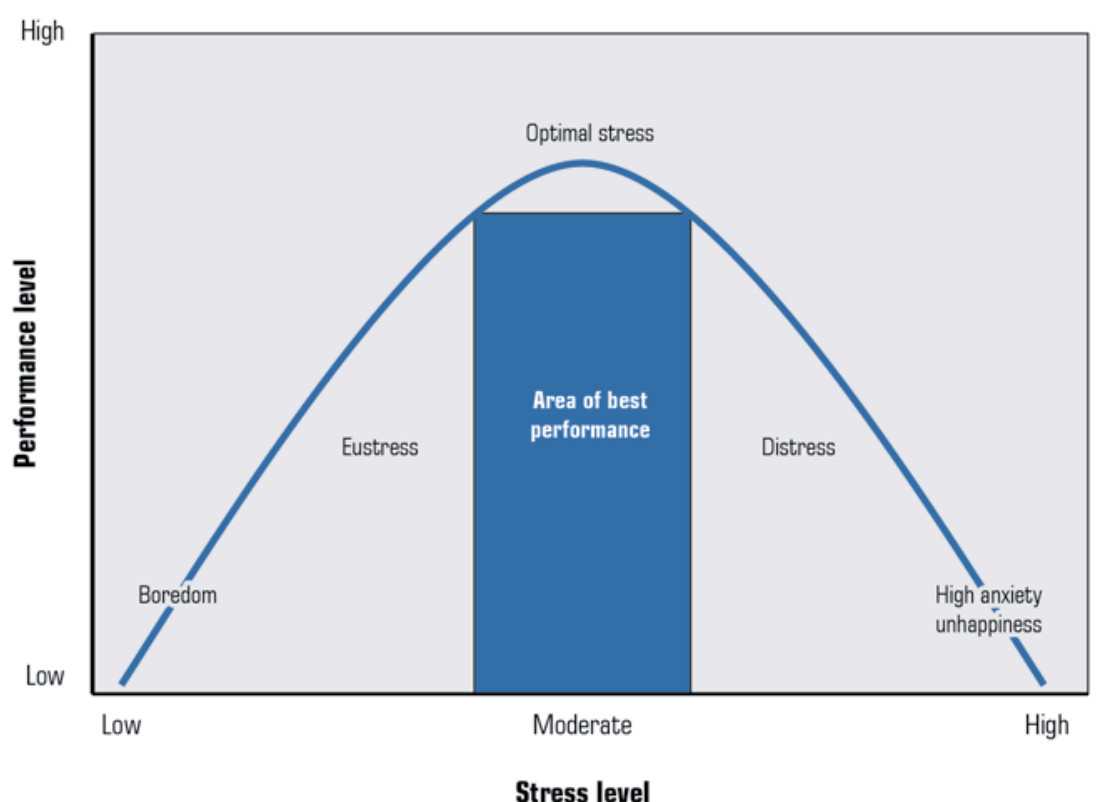

Physical Signs

- Tachycardia, breathless breatbing

- Migraine

- Backpain

- Digestive disorders

- Dry mouth

- Buzzing

- Sweating in the hands

Behavioral Signs

- Compulsive cherwing gum

- Being hypercritical towards others

- Bruxism

- Alcohol abuse

- Food disorders

\section{Emotional Signs}

- Frequent crying

- Boredom, loss of meaning

- Feeling of impotence towards change

- Solitude

- Unmotivated sadness

Cognitive Signs

- Lack of creativity

- Memory loss

- Constant concern

- Loss of sense of humor

- Decision-making incapacity
The most common distress signs are listed in the box [7].

Some of them are more often referred to as "medically unexplained symptoms" or MUS [8]. Several studies showed that $15-30 \%$ of patients in primary health care area have MUS, i.e. physical symptoms without evidence of underlying diseases [9]. Frequently, MUS require urgent diagnostic tests and hospitalizations, whose costs burden the already overwhelmed health systems. According to a multicenter study, which analyzed almost 100,000 patients, MUS are reliable indices of chronic stress and inflammation [10].

It is up to healthcare professionals to agree on a comprehensive action plan with the patient in order to eradicate his/her symptoms [11].

\section{POSSIBLE SOLUTIONS}

Helping people managing the stress is equivalent to teach the resilience. The resilience is the ability to overcome stress in an adaptive way, maintaining at the same time the normal psychological and physical functioning [12-14].

Resilience could be learnt in several ways.

Resilience may be improved through the development of life skills. The World Health Organization (WHO) defined "life skills" as «abilities for adaptive and positive behavior that enable individuals to deal effectively with the demands and challenges of everyday life» [15]. According to WHO, life skills are: 
- decision making;

- problem solving;

- creative thinking;

- critical thinking;

- effective communication;

- interpersonal relationship skills;

- self-awareness;

- empathy;

- coping with emotions; and

- coping with stress.

These qualities could be better developed by ad hoc programs targeting children and teenagers, which have been prepared by WHO itself and are recommended in schools.

Among the most important steps towards the management of stress, there is a healthy lifestyle, which includes mainly healthy diet and physical activity.

Chronic stress may alter glucose metabolism, promote insulin resistance, affect leptin, ghrelin and hypothalamic neuropeptides [16], and trigger the secretion of glucocorticoid hormones, which favor the deposition of abdominal fat [17]. In addition, the rewarding properties of comfort food may help people feel better. On the other side, scientific evidence underline that a healthy diet may help in the treatment of several pathologies.

However, physicians, before prescribing a diet, should help patients know their own targets, rhythms, limits, teaching also how to relax and reward themselves in order to reduce stress in a natural way. Otherwise, even if an energy-restricted diet is prescribed, metabolism slows down and results in weight gain (thrifty metabolism [18]).

The exercise results in an increase in the volume of muscle fibers and in the ability to manage stress, as it increases glycogen and therefore the energy available. In addition, it may trigger endorphin release, thus contributing to the creation of the "flow" [19], a mental status of deep well-being and pleasure, known to be related to the development of resilience [20]. Finally, physical activity delays cell senescence [21] and results in the release of brain derived neurotrophic factor (BDNF), which increases cerebral plasticity [22].

Also in this case the physician prescribing physical activity to stressed patients should be careful while suggesting type, timetable, and mode, since they have to be chosen according to the individual's preferences, body composition, and circadian rhythms, in order to avoid the development of further stress.

Lifestyle Medicine deals exactly with the dissemination of the knowledge regarding the importance of exercise, healthy diet, behavioral change and self-care, and the eradication of unhealthy lifestyles, including also tobacco addiction. Healthy lifestyles have been proven effective in the reduction of all-cause mortality [23]. Several associations and initiatives all over the world promote Lifestyle Medicine [24-29].

Professor Herbert Benson, starting from the known mutual influence between mind and body, pioneered and refined the MindBody Medicine, another effective mode to manage stress. Since the increased emotional stress results in the onset and worsening of physical symptoms of malaise and exacerbates clinical conditions, Benson suggested that mind-body therapies have significant therapeutic effects in several pathological conditions, eliciting an intrinsic anti-stress response, which includes a reduction in the sympathetic and cerebral cortical activity [30]. He called this intrinsic response to stress "relaxation response" and found that it can be elicited by prayers (in every religious tradition) and meditative practices.

His colleague Jon Kabat-Zinn chose one of them, Vipassana meditation, and turned it in an appreciated occidental version, called “mindfulness" [31]. Mindfulness

- improves immune system [32];

- reduces pain [33];

- reduces cell inflammation [34];

- reduces depression [35]; and

- reduces anxiety and stress [36].

It consists in paying attention on purpose, in the present moment, and non-judgmentally [37]. This technique could be learnt in Professor Kabat-Zinn's clinic, Center for Mindfulness in Medicine, Health Care, and Society at the University of Massachusetts Medical School [38], but also in several other centers all over the world, as its success was planetary.

Finally, several environmental and good habits may help reduce stress, such as:

- everything eliciting the flow [19];

- music [39];

- creativity [40];

- rituals [41]; and

- sense of humor $[42,43]$. 


\section{STRESS IN ORGANIZATIONS}

Stress may affect also organizations. This phenomenon occurs especially during or before a change. As in individuals, in order to avoid pathological consequences, the organization should be resilient.

The resilience of an organization may be assessed through analyzing protection factors in processes concerning efficacy and efficiency. The WHO developed international standards for the self-assessment [44] in healthcare settings by means of Health Promoting Hospitals \& Health Services (HPH) strategy [45], putting in place the Ottawa Charter for Health Promotion [26].

An Italian compendium about standards 1 and 4 focusing on psycoemotional well-being has been developed [46]. It aims at being used in parallel with the risk assessment and promoting the organizational and personnel empowerment concerning the protection factors of health at work. It comes of a rapid self-assessment model on three levels: top management, staff, and individual.

\section{CONCLUSION}

Although stress is necessary to face changes and obtain goals, its permanence and too elevated levels may negatively affects several aspects of people's life, influencing also the course of pathologies and determining itself signs and symptoms. However, several techniques to reach a psychological balance can be learnt.

Patients should rely on healthcare professionals able to teach these techniques or to refer them to the most suitable teachers, according to the patient's nature and preferences.

Similarly, pathological consequences of stress in organizations should be prevented through specific standards for self-assessment developed by WHO.

\section{Funding}

This article has been published without the support of sponsors.

\section{Conflicts of Interests}

The Authors published with SEEd the book "100 domande sulla gestione dello stress".

\section{To know more}

\section{0 domande sulla gestione dello stress}

(available in Italian)

Cristina Aguzzoli, Anna Maria De Santi

First edition April 2018

$\begin{array}{ll}\text { Paperback } & \text { Ebook } \\ \text { ISBN978-88-97419-51-8 } & \text { ISBN978-88-97419-52-5 } \\ 17 \times 24 \mathrm{~cm} & \text { Price: } 5,99 € \\ \text { Price: } 15,00 € & \end{array}$

Purchase on www.edizioniseed.it and Amazon

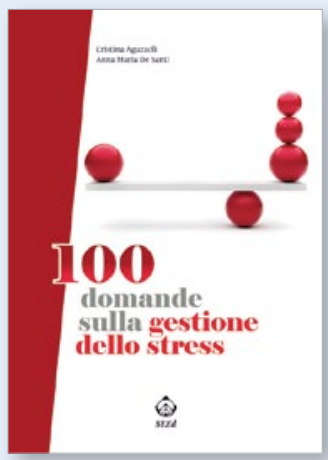

Stress is a common issue, especially in the modern society.

This book aims at guiding healthcare professionals towards a greater knowledge about both physiological and pathological mechanisms underlying stress in the first phases of life and in the adulthood, helping them recognizing the physical, psychological, and behavioral consequences, suggesting structured techniques and practical tips tailored according to the psychological characteristics of patients, and providing the tools necessary to understand and manage the work-related stress.

The text is made up of 100 short questions concerning 6 aspects of the topic: every question is stand-alone and is enriched by several intratextual links to other questions, where a specific aspect is treated in detail.

The presentation is by Ranieri Guerra, WHO Assistant Director-General 


\section{REFERENCES}

1. Benson-Henry Institute for Mind Body Medicine at Massachusetts General Hospital.https:// www.bensonhenryinstitute.org/ (last accessed May 2018)

2. Cannon WB. Bodily changes in pain, hunger, fear and rage. Whitefish, MT (USA): Literary Licensing, LLC, 2014. Original title: "Bodily changes in pain, hunger, fear and rage", 1920

3. Chrousos GP. Stress and disorders of the stress system. Nat Rev Endocrinol 2009; 5: 374-81

4. Chrousos GP, Kino T. Intracellular glucocorticoid signaling: a formerly simple system turns stochastic. Sci STKE 2005; 2005: pe48

5. Yerkes RM, Dodson JD. The relation of strength of stimulus to rapidity of habit-formation. Journal of Comparative Neurology and Psychology 1908; 18: 459-82

6. Diamond DM, Campbell AM, Park CR, et al. The temporal dynamics model of emotional memory processing: a synthesis on the neurobiological basis of stress-induced amnesia, flashbulb and traumatic memories, and the Yerkes-Dodson law. Neural Plast 2007; 2007: 60803

7. Aguzzoli C, Tunini C. Emozioni e gestione dello stress. In: De Santi A, Fabio V, Filipponi F, et al. (a cura di). La promozione della salute nelle scuole. Attività pratiche su: salute mentale, life skills, educazione ai media, bullismo e sessualità. Roma: Istituto Superiore di Sanità, 2008. Rapporti ISTISAN 08/21. Available at http://www.iss.it/binary/publ/cont/0821.pdf (last accessed May 2018)

8. Rosendal M, Fink P, Falkoe E, et al. Improving the classification of Medically Unexplained Symptoms in Primary Care. Eur J Psychiat 2007; 21: 25-36

9. Kirmayer LJ, Groleau D, Looper KJ, et al. Explaining medically unexplained symptoms. Can J Psychiatry 2004; 49: 663-72

10. Tsigos C, Stefanaki C, Lambrou GI, et al. Stress and inflammatory biomarkers and symptoms are associated with bioimpedance measures. Eur J Clin Invest 2015; 45: 126-34

11. Hatcher S, Arroll B. Assessment and management of medically unexplained symptoms. BMJ 2008; 336: 1124-8

12. Russo SJ, Murrough JW, Han MH, et al. Neurobiology of resilience. Nat Neurosci 2012; 15: 1475-84

13. Rutter M. Resilience as a dynamic concept. Dev Psychopathol 2012; 24: 335-44

14. Southwick SM, Charney DS. The science of resilience: implications for the prevention and treatment of depression. Science 2012; 338: 79-82

15. World Health Organization. Programme on mental health: life skills in schools. WHO/MNH/ PSF/93.7A Rev. 2. Geneva: WHO, 1997. Available at http://apps.who.int/iris/bitstream/ handle/10665/63552/WHO_MNH_PSF_93.7A_Rev.2.pdf?sequence=1 (last accessed May 2018)

16. Adam TC, Epel ES. Stress, eating and the reward system. Physiol Behav 2007; 91: 449-58

17. Dallman MF, Pecoraro NC, la Fleur SE. Chronic stress and comfort foods: self-medication and abdominal obesity. Brain Behav Immun 2005; 19: 275-80

18. Straub R. The origin of chronic inflammatory systemic diseases and their sequelae. Cambridge, MA (USA): Academic Press, 2015

19. Csíkszentmihályi M. Beyond boredom and anxiety. San Francisco, CA (USA):Jossey-Bass, 1975

20. Agnoletti M. Le esperienze ottimali, la resilienza e lo stress. PNEI NEWS 2015; 1: 7-10

21. Cherkas LF, Hunkin JL, Kato BS, et al. The association between physical activity in leisure time and leukocyte telomere length. Arch Intern Med 2008; 168: 154-8

22. Sleiman SF, Henry J, Al-Haddad R, et al. Exercise promotes the expression of brain derived neurotrophic factor (BDNF) through the action of the ketone body $\beta$-hydroxybutyrate. Elife 2016; 5: e15092

23. Loef $\mathrm{M}$, Walach $\mathrm{H}$. The combined effects of healthy lifestyle behaviors on all cause mortality: a systematic review and meta-analysis. Prev Med 2012; 55: 163-70

24. Exercise is Medicine ${ }^{\circledR}$ (EIM). http://www.exerciseismedicine.org/ (last accessed May 2018)

25. True Health Initiative. http://www.truehealthinitiative.org/ (last accessed May 2018)

26. World Health Organization. The Ottawa Charter for health promotion. First International Conference on Health Promotion, Ottawa, 21 November 1986. Available at http://www.who. int/healthpromotion/conferences/previous/ottawa/en/ (last accessed May 2018)

27. American College of Lifestyle Medicine. www.lifestylemedicine.org (last accessed May 2018)

28. Institute of Lifestyle Medicine. www.instituteoflifestylemedicine.org (last accessed May 2018) 
29. Italian Lifestyle Medicine. www.italianlifestylemedicine.org (last accessed May 2018)

30. Benson H. The relaxation response. Updated and expanded version. New York, NY (USA): HarperCollins, 2000. Original title: "The relaxation response", 1975

31. Kabat-Zinn J. Bringing mindfulness to medicine: an interview with Jon Kabat-Zinn, PhD. Interview by Karolyn Gazella. Altern Ther Health Med 2005; 11: 56-64

32. Davidson RJ, Kabat-Zinn J, Schumacher J, et al. Alterations in brain and immune function produced by mindfulness meditation. Psychosomatic Med 2003; 65: 564-70

33. Zeidan F, Martucci KT, Kraft RA, et al. Brain mechanisms supporting modulation of pain by mindfulness meditation. J Neurosc 2011; 31: 5540-8

34. Rosenkranz MA, Davidson RJ, Maccoon DG, et al. A comparison of mindfulness-based stress reduction and an active control in modulation of neurogenic inflammation. Brain Behav Immun 2013; $27: 174-84$

35. Ramel W, Goldin PR, Carmona PE. The effects of mindfulness meditation on cognitive processes and affect in patients with past depression. Cognitive Therapy and Research 2004; 28: 433-55

36. Miller JJ, Fletcher K, Kabat-Zinn J. Three-year follow-up and clinical implications of a mindfulness meditation-based stress reduction intervention in the treatment of anxiety disorders. Gen Hosp Psychiatry 1995; 17: 192-200

37. Kabat-Zinn J. Wherever you go, there you are: mindfulness meditation in everyday life. New York, NY (USA): Hyperion, 1994

38. Center for Mindfulness in Medicine, Health Care and Society. https://www.umassmed.edu/ $\mathrm{cfm} /$ (last accessed May 2018)

39. Nakayama H, Kikuta F, Takeda H. A pilot study on effectiveness of music therapy in hospice in Japan.J Music Ther 2009; 46: 160-72

40. Yorks L, Kasl E. I know more than I can say: a taxonomy for using expressive ways of knowing to foster transformative learning. J Transform Educ 2006; 4: 43-64

41. Ben-Shahar T. Happier: learn the secrets to daily joy and lasting fulfillment. New York, NY (USA): McGraw-Hill Education, 2007, p. 192

42. Berk LS, Tan SA, Fry WF, et al. Neuroendocrine and stress hormone changes during mirthful laughter. Am J Med Sci 1989; 298: 390-6

43. Yovetich NA, Dale JA, Hudak MA. Benefits of humor in reduction of threat-induced anxiety. Psychol Rep 1990; 66: 51-8

44. Groene $\mathrm{O}$ (a cura di). Implementing health promotion in hospitals: Manual and self-assessment forms. Geneva:World Health Organization, 2006.Available at http:/www.euro.who.int/_data/ assets/pdf_file/0009/99819/E88584.pdf (last accessed May 2018)

45. The International Network of Health Promoting Hospitals and Health Services. www.hphnet. org (last accessed May 2018)

46. Aguzzoli C, Giacomini L, Della Vedova A, et al.; gruppo di lavoro sul benessere psicoemozionale. Come sostenere la valutazione sul benessere psicoemozionale nelle Aziende Sanitarie? Un contributo dalla rete HPH del Friuli Venezia Giulia. Health Promoting Hospitals, 2010. Available at http://www.retehphfvg.it/InfoCMS/RepositPubbl/table7/10/Allegati/standard\%20 1-4\%20HPH\%20ITALIANO.pdf (last accessed May 2018) 